\title{
HUBUNGAN FAKTOR-FAKTOR PERILAKU SEHAT DENGAN KETIDAKPATUHAN DIET PADA PENDERITA DIABETES MELLITUS DI POLIKLINIK PENYAKIT DALAM RSUD DR. M. YUNUS KOTA BENGKULU TAHUN 2013
}

\author{
dr. Hernita Taurustya \\ Fakultas Kedokteran dan IImu Kesehatan Universitas Bengkulu \\ e-mail: hernitataurustya.dr@gmail.com
}

\begin{abstract}
ABSTRAK
Latar Belakang: Diabetes Mellitus (DM) merupakan salah satu masalah kesehatan khususnya di Propinsi Bengkulu yang masih tinggi. Keberhasilan perencanaan makanan tergantung pada perilaku penderita DM dalam menjalani anjuran makan yang diberikan. Perilaku kesehatan di pengaruhi oleh tiga teori penyebab masalah kesehatan yaitu faktor predisposisi, faktor pemungkin, dan faktor penguat. Tujuan penelitian ini adalah untuk mengetahui hubungan faktor-faktor dengan ketidakpatuhan diet pada penderita DM.

Metode: Penelitian ini menggunakan metode deskriptif analitik dengan desain penelitian cross sectional. Tehnik pengambilan sampel pada penelitian ini dengan sample random sampling. Sampel pada penelitian ini berjumlah 97 orang yang keseluruhannya adalah penderita DM yang berobat di Poliklinik Penyakit Dalam RSUD Dr. M.Yunus Kota Bengkulu. Pengambilan data dilakukan dengan menggunakan kuesioner dan wawancara secara langsung dengan responden. Data penelitian dianalisa dengan menggunakan tabel distribusi dan uji chi-square, yang hasilnya disajikan dalam bentuk tabel dan narasi.

Hasil: Hasil analisis univariat, distribusi frekuensi faktor predisposisi (pengetahuan mengenai DM) dari 97 responden, sebagian besar responden yaitu 59 orang $(60,8 \%)$ tidak baik. Distribusi frekuensi faktor pemungkin (perilaku kesehatan) dari 97 responden, sebagian besar responden yaitu 61 orang $(62,89 \%)$ tidak baik. Distribusi frekuensi faktor penguat (dukungan keluarga) dari 97 responden, hampir sebagian dari responden yaitu 36 orang $(37,11 \%)$ tidak baik. Distribusi frekuensi ketidakpatuhan diet dari 97 responden, sebagian besar responden yaitu 68 orang $(70,10 \%)$ tidak patuh terhadap diet DM. Hasil analisis bivariat, ada hubungan faktor predisposisi dengan ketidakpatuhan diet pada penderita DM dengan nilai $\rho=0,000$, ada hubungan faktor pemungkin dengan ketidakpatuhan diet pada penderita DM dengan nilai $\rho=0,000$ dan ada hubungan faktor penguat dengan ketidakpatuhan diet pada penderita DM di Poliklinik Penyakit Dalam RSUD Dr. M.Yunus Kota Bengkulu tahun 2013 dengan nilai $\rho=0,000$.

Kesimpulan: Adanya hubungan faktor-faktor perilaku kesehatan (faktor predisposisi, faktor pemungkin, dan faktor penguat) dengan ketidakpatuhan diet pada penderita DM di Poliklinik Penyakit Dalam RSUD Dr. M. Yunus Kota Bengkulu Tahun 2013.
\end{abstract}

Kata Kunci: Perilaku Kesehatan, Ketidakpatuhan Diet, Penderita DM

\section{FACTORS RELATED HEALTH BEHAVIOR IN PATIENTS WITH DIET NONCOMPLIANCE DIABETES MELLITUS AT THE POLYCLINIC INTERNAL MEDICINE IN RSUD DR. M. YUNUS HOSPITAL OF BENGKULU CITY IN 2013}

\author{
dr. Hernita Taurustya \\ Faculty of Medicine and Health Sciences, University of Bengkulu \\ e-mail: hernitataurustya.dr@gmail.com
}

\begin{abstract}
Background: Diabetes Mellitus (DM) is one health problem, especially in Bengkulu is still high. Meal planning success depends on the behavior of people with diabetes to live a suggestion to eat given. Health behavior is influenced by three theories that cause health problems predisposing factors, enabling factors and reinforcing factors. The purpose of this study was to determine the relationship of the factors with diet noncompliance in patients with DM.

Methods: This study used a descriptive analytic method with cross sectional study design. Sampling technique in this study with a sample random sampling. Samples in this study amounted to 97 people and all are DM patients who seek treatment at the Polyclinic Internal Medicine Hospital Dr. M.Yunus city of Bengkulu. Data were collected using questionnaires and direct interviews with respondents.
\end{abstract}


Data were analyzed using distribution tables and chi-square test, whose results are presented in tabular form and narrative.

Results: The results of the univariate analysis, frequency distribution predisposing factors (knowledge of DM) of the 97 respondents, the majority of respondents, $59(60.8 \%)$ was not good. The frequency distribution of the enabling factors (behavioral health) of the 97 respondents, the majority of respondents, 61 people $(62.89 \%)$ is not good. The frequency distribution amplifier factor (family support) of the 97 respondents, almost half of respondents, 36 people $(37.11 \%)$ is not good. The frequency distribution of non-compliance with the diet of 97 respondents, the majority of respondents, 68 people $(70.10 \%)$ did not adhere to the diet DM. The results of the bivariate analysis, no association predisposing factors disobedience diet in patients with diabetes mellitus with the value $\rho=0,000$, there is a relationship enabling factor disobedience diet in patients with diabetes mellitus with the value $\rho=0.000$ and there is a correlation factor of the amplifier with noncompliance diet in patients with DM at the Polyclinic Internal Medicine Hospital Dr. M.Yunus Bengkulu City in 2013 with a value of $\rho=0.000$.

Conclusion: The existence of a relationship of health behavioral factors (predisposing, enabling factors and reinforcing factors) with a diet of non-compliance in patients with DM at the Polyclinic Internal Medicine Hospital Dr. M. Yunus Bengkulu City in 2013.

\section{Keywords: Behavioral Health, Noncompliance Diet, Patient DM}

\section{PENDAHULUAN}

Tujuan Pembangunan kesehatan
adalah meningkatkan derajat kesehatan
masyarakat dan pemberatasan penyakit
menular, program ini bertujuan untuk menurunkan angka kesakitan, kematian, dan kecacatan sebagai unsur kesejahteraan umum, untuk pencegahan serta mengurangi dampak sosial akibat penyakit sehingga tidak menjadi masalah kesehatan. ${ }^{1}$ Dari hasil pencatatan penderita DM di Propinsi Bengkulu tahun 2011 terdapat 2.041 orang pasien dan ter dapat 28 orang pasien yang meninggal dunia. ${ }^{1}$

Diabetes mellitus (DM) merupakan salah satu penyakit degeneratif kronis yang semakin meningkat prevalensinya di masa mendatang. Indonesia menempati peringkat keempat negara dengan penderita DM terbanyak di dunia. World Heatlh Organization
(WHO) 2009, memprediksi kenaikan jumlah pasien DM di Indonesia dari 8.4 juta pada tahun 2000 menjadi 21.3 juta pada tahun 2030. Salah satu faktor penyebab tingginya prevalensi DM adalah pola makan yang tidak sehat meliputi diet tinggi karbohidrat dan lemak, kebiasaan mengkonsumsi makanan siap saji dengan kandungan natrium tinggi, dan konsumsi makanan rendah serat. ${ }^{2}$

Perkembangan ilmu dan teknologi kedokteran telah banyak menyelamatkan nyawa manusia. Penyakit-penyakit yang selama ini tidak terdiagnosis dan terobati sekarang sudah banyak yang teratasi. Tetapi untuk memperbaiki taraf kesehatan secara global, tidak dapat mengandalkan hanya pada tindakan kuratif, karena penyakit-penyakit seperti DM sebagian besar komplikasinya dapat dicegah dengan tetap berperilaku pola hidup yang sehat (aktivitas fisik yang teratur 
dan diet makanan) dan menjauhi pola hidup berisiko. $^{3}$

Empat pilar utama pengelolaan Diabetes mellitus (DM) adalah perencanaan makan, latihan jasmani, obat berkhasiat hipoglikemik, dan penyuluhan. Perencanaan makan merupakan komponen utama keberhasilan penatalaksanaan DM. Perencanaan makan bertujuan membantu penderita DM memperbaiki kebiasaan makan sehingga dapat mengendalikan kadar glukosa, lemak, dan tekanan darah.

Berdasarkan hasil sistem pencatatan dan pelaporan terpadu puskesmas tahun 2011, di kota Bengkulu penyakit DM menduduki urutan ke-2 dari 12 kasus penyakit tidak menular yang diamati. Dan di rumah sakit rujukan daerah Provinsi Bengkulu RSUD Dr. M.Yunus jumlah kasus penderita DM menduduki urutan ke-4 dari 10 kasus penyakit terbanyak yang ditemukan pada tahun 2010 dan 2011 dengan insidensi kasus baru yang semakin meningkat tiap tahunnya. ${ }^{1}$

Keberhasilan perencanaan makan bergantung pada perilaku penderita Diabetes Mellitus (DM) dalam menjalani anjuran makan yang diberikan. Ketidakpatuhan pasien dalam perencanaan makan merupakan salah satu kendala dalam pengobatan DM. Data laporan WHO tahun 2003 menunjukkan hanya 50\% pasien DM di negara maju mematuhi pengobatan yang diberikan. Perilaku terkait kepatuhan diet merupakan suatu hal yang spesifik dan berbeda antar individu sehingga diperlukan penelitian secara mendalam terhadap setiap subjek penelitian. Green dan Kreuter mengajukan sebuah kerangka teori (Green) yang mempelajari mengenai faktorfaktor yang berkaitan dengan perilaku sehat seseorang mencakup faktor predisposisi, pemungkin, dan penguat dimana tepat digunakan untuk meneliti perilaku kesehatan individu dengan penyakit kronik. Teori Green merupakan model yang tepat bagi penanganan pasien DM karena terbukti dapat meningkatkan kepatuhan kontrol gula darah pasien. ${ }^{4}$

RSUD Dr. M.Yunus sebagai rumah sakit rujukan dari semua daerah di Provinsi Bengkulu mempunyai peran penting dalam menunjang program pencegahan primer DM. Berdasarkan hal-hal tersebut diatas, maka peneliti tertarik untuk melakukan penelitian tentang " Hubungan Faktor- faktor Perilaku Sehat Dengan Ketidakpatuhan Diet Pada Penderita DM di Poliklinik Penyakit Dalam RSUD Dr. M.Yunus Kota Bengkulu tahun 2013". 
METODE

Penelitian ini merupakan jenis

penelitian deskriptif- analitik dengan pendekatan cross sectional. Tehnik pengambilan sampel pada penelitian ini dengan sample random sampling. Sampel pada penelitian ini berjumlah 97 orang yang keseluruhannya adalah penderita DM yang berobat di Poliklinik Penyakit Dalam RSUD Dr. M.Yunus Kota Bengkulu. Pengambilan data dilakukan dengan menggunakan kuesioner dan wawancara secara langsung dengan responden. Data penelitian dianalisa dengan menggunakan tabel distribusi dan uji chisquare, yang hasilnya disajikan dalam bentuk tabel dan narasi.

HASIL

A. Analisis Univariat

Analisis ini dilakukan untuk mengetahui distribusi frekuensi faktor-faktor ketidakpatuhan diet dengan penderita DM di Poliklinik Penyakit Dalam RSUD Dr.M.Yunus Kota Bengkulu tahun 2013.

Tabel 1. Distribusi Frekuensi Faktor Predisposisi pada Penderita DM di Poliklinik Penyakit Dalam RSUD Dr.M.Yunus Kota Bengkulu Tahun 2013

Faktor Predisposisi Baik
Frekuensi

\section{Persentase}

Tidak Baik 59 $60,8 \%$

Tabel 1 diatas menunjukan bahwa dari 97 responden sebagian besar dari responden yaitu berjumlah 59 orang $(60,8 \%)$ memiliki faktor predisposisi (pengetahuan) tidak baik

Tabel 2. Distribusi Frekuensi Faktor Pemungkin pada Penderita DM di Poliklinik Penyakit

Dalam RSUD Dr.M.Yunus Kota Bengkulu Tahun 2013

Faktor Pemungkin
Frekuensi

\section{Persentase}

\begin{tabular}{ccc}
\hline Baik & 36 & $37,11 \%$ \\
& & \\
\hline Tidak Baik & 61 & $62,89 \%$ \\
& & \\
\hline
\end{tabular}

Tabel 2 diatas menunjukan bahwa dari

97 responden sebagian besar dari responden 
yaitu berjumlah 61 orang $(62,89 \%)$ memiliki baik.

faktor pemungkin (perilaku kesehatan) tidak

Tabel 3. Distribusi Frekuensi Faktor Penguat pada Penderita DM di Poliklinik Penyakit Dalam RSUD Dr.M.Yunus Kota Bengkulu Tahun 2013

$\begin{array}{lll}\text { Faktor Penguat } \quad \text { Frekuensi } & \text { Persentase }\end{array}$

\begin{tabular}{ccc}
\hline Baik & 61 & $62,89 \%$ \\
& & \\
\hline Tidak Baik & 36 & $37,11 \%$
\end{tabular}

Tabel 3 diatas menunjukan bahwa dari 97 yaitu berjumlah 36 orang (37,11\%) memiliki responden hampir sebagian dari responden faktor penguat (dukungan keluarga) tidak baik.

Tabel 4. Distribusi Frekuensi Ketidakpatuhan Diet pada Penderita DM di Poliklinik Penyakit Dalam RSUD Dr.M.Yunus Kota Bengkulu Tahun 2013
Ketidakpatuhan Diet
Frekuensi
Persentase

\begin{tabular}{ccc}
\hline Patuh & 29 & $29,90 \%$ \\
& & \\
\hline Tidak Patuh & 68 & $70,10 \%$ \\
\hline
\end{tabular}

Tabel 4 diatas menunjukan bahwa dari

yaitu berjumlah 68 orang $(70,10 \%)$ tidak patuh

97 responden sebagian besar dari responden terhadap diet DM.

\section{B. Analisis Bivariat}

1. Hubungan Faktor Predisposisi dengan

Ketidakpatuhan Diet Pada Perita DM

di Poliklinik Penyakit Dalam RSUD Dr.

M. Yunus Kota Bengkulu Tahun 2013. 
Tabel 5. Hubungan Faktor Predisposisi dengan Ketidakpatuhan Diet pada Penderita DM Di Poliklinik Penyakit Dalam RSUD Dr.M.Yunus Kota Bengkulu Tahun 2013

\section{Ketidakpatuhan Diet pada}

Faktor

Penderita DM

Total

$\mathbf{P}$

Presdisposisi

Tidak Patuh Patuh

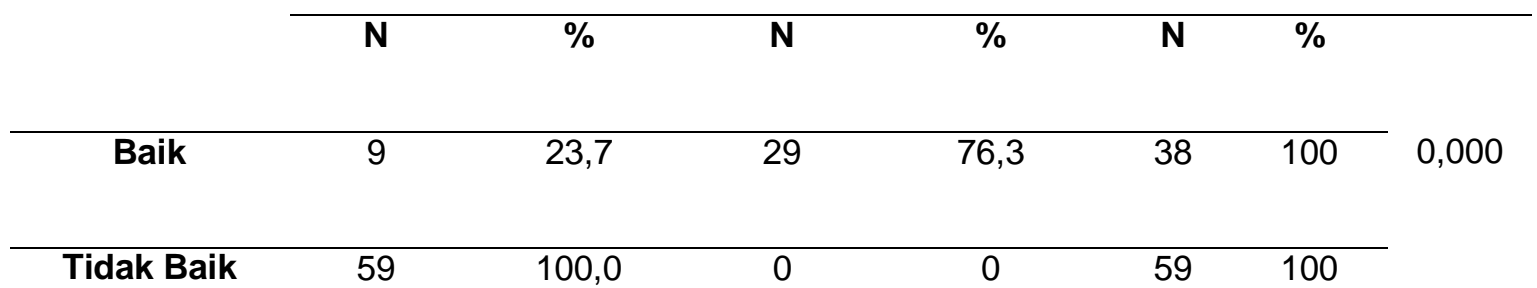

Berdasarkan tabel 5 diatas menunjukan bahwa dari 38 responden dengan pengetahuan baik (faktor predisposisi) terdapat sebagian besar dari responden $(76,3 \%)$ patuh terhadap diet DM dan hampir sebagian responden $(23,7 \%)$ tidak patuh terhadap diet DM. Sedangkan dari 59 responden dengan pengetahuan tidak baik tidak terdapat satupun dari responden $(0 \%)$ patuh terhadap diet DM dan seluruh responden (100\%) tidak patuh terhadap diet DM.

Berdasarkan hasil uji statistik hubungan faktor predisposisi (pengetahuan) dengan Ketidakpatuhan Diet Pada Penderita DM di Poliklinik Penyakit Dalam RSUD Dr.M.Yunus Kota Bengkulu menggunakan perhitungan Chisquare $\left(x^{2}\right)$ yaitu Continuity Correction diperoleh nilai $\rho=0,000(\rho<0,05)$ yang berarti bahwa ada hubungan yang bermakna antara faktor predisposisi (pengetahuan) dengan
Ketidakpatuhan Diet Pada Penderita DM di Poliklinik Penyakit Dalam RSUD Dr.M.Yunus Kota Bengkulu.

2. Hubungan Faktor Pemungkin dengan

Ketidakpatuhan Diet Pada Penderita DM di

Poliklinik Penyakit Dalam RSUD Dr.M.Yunus

Kota Bengkulu. 
Tabel 6. Hubungan Faktor Pemungkin dengan Ketidakpatuhan Diet pada Penderita DM Di Poliklinik Penyakit Dalam RSUD Dr.M.Yunus Kota Bengkulu Tahun 2013

\section{Ketidakpatuhan Diet pada}

Faktor

Penderita DM

Total

$\rho$

Pemungkin

Tidak Patuh

Patuh

\begin{tabular}{cccccccc} 
& $\mathbf{N}$ & $\%$ & $\mathbf{N}$ & $\%$ & $\mathbf{N}$ & $\%$ \\
& & & & & & \\
\hline Baik & 7 & 19,4 & 29 & 80,6 & 36 & 100 & 0,000 \\
& & & & & & \\
\hline Tidak Baik & 61 & 100 & 0 & 0 & 61 & 100
\end{tabular}

Berdasarkan tabel 6 diatas menunjukan bahwa dari 36 responden dengan perilaku kesehatan baik (faktor pemungkin) terdapat hampir seluruh responden $(80,6 \%)$ patuh terhadap diet DM dan sebagian kecil dari responden $(19,4 \%)$ tidak patuh terhadap diet DM. Sedangkan dari 61 responden dengan perilaku kesehatan tidak baik tidak terdapat satupun dari responden $(0 \%)$ patuh terhadap diet DM dan seluruh responden (100\%) tidak patuh terhadap diet DM. Berdasarkan hasil uji statistik hubungan faktor pemungkin (perilaku kesehatan) dengan Ketidakpatuhan Diet Pada Lansia Penderita DM di Poliklinik Penyakit Dalam RSUD M. Yunus Kota Bengkulu menggunakan perhitungan Chi-square $\left(x^{2}\right)$ yaitu Fisher's exact test diperoleh nilai $\rho=0,000(\rho<$ $0,05)$ yang berarti bahwa ada hubungan antara faktor pemungkin (perilaku kesehatan) dengan Ketidakpatuhan Diet Pada Penderita DM di Poliklinik Penyakit Dalam RSUD Dr.M.Yunus Kota Bengkulu. Hubungan Faktor Penguat dengan Ketidakpatuhan Diet Pada Penderita DM di Poliklinik Penyakit Dalam RSUD Dr.M.Yunus Kota Bengkulu. 
Tabel 7. Hubungan Faktor Penguat dengan Ketidakpatuhan Diet pada Penderita DM Di

Poliklinik Penyakit Dalam RSUD Dr.M.Yunus Kota Bengkulu Tahun 2013

Ketidakpatuhan Diet pada

Faktor

Penderita DM

Total

$\mathbf{P}$

Penguat

Tidak Patuh

Patuh

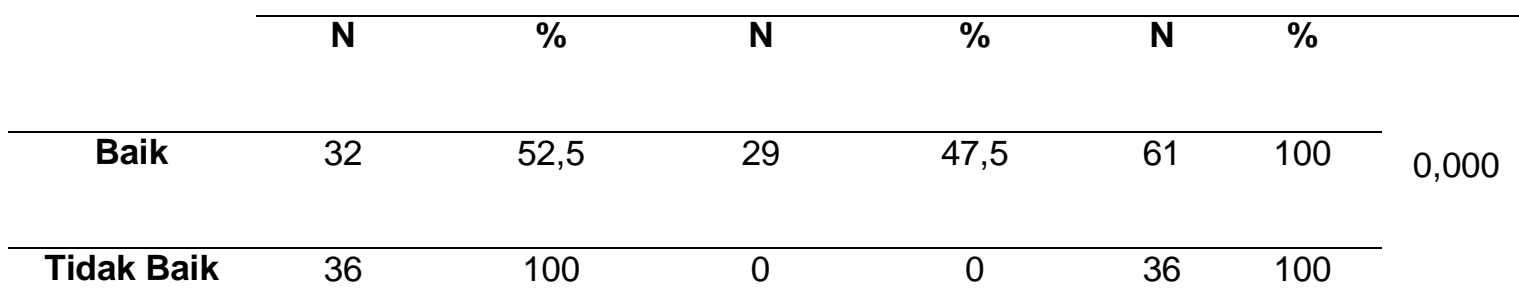

Berdasarkan tabel 7 diatas menunjukan bahwa dari 61 responden dengan dukungan keluarga baik (faktor penguat) terdapat hampir sebagian dari responden $(47,5 \%)$ patuh terhadap diet DM dan sebagian besar dari responden $(52,5 \%)$ tidak patuh terhadap diet DM. Sedangkan dari 36 responden dengan dukungan keluarga tidak baik, tidak terdapat satupun dari responden ( $0 \%)$ patuh terhadap diet DM dan seluruh responden (100\%) tidak patuh terhadap diet DM.

Berdasarkan hasil uji statistik hubungan faktor penguat (dukungan keluarga) dengan Ketidakpatuhan Diet Pada Penderita DM di Poliklinik Penyakit Dalam RSUD Dr.M. Yunus Kota Bengkulu menggunakan perhitungan Chi-square $\left(\mathrm{x}^{2}\right)$ yaitu Continuity Correction diperoleh nilai $\rho=0,000(\rho<0,05)$ yang berarti bahwa ada hubungan antara faktor penguat (dukungan keluarga) dengan Ketidakpatuhan Diet Pada Penderita DM di

Poliklinik Penyakit Dalam RSUD Dr.M.Yunus Kota Bengkulu.

\section{PEMBAHASAN}

\section{Faktor Predisposisi}

Hasil penelitian menunjukan bahwa dari 97 responden terdapat sebagian besar dari responden yaitu berjumlah 59 orang $(60,8 \%)$ memiliki faktor predisposisi (Pengetahuan) tidak baik. Hal ini menunjukan masih ada penderita DM di Poliklinik Penyakit Dalam RSUD Dr. M. Yunus yang memiliki pengetahuan tidak baik dalam hal penyakit DM dan program dietnya.

Dari hasil penelitian di Poliklinik Penyakit Dalam RSUD Dr. M. Yunus peneliti 
melihat masih ada penderita DM yang tidak mengetahui pengertian, tanda, penyebab, pengelolahan dan pengaturan/perencanaan makan pada DM, dimana pengetahuan, motivasi dan kepercayaan penderita DM untuk mengatur pola makan dan patuh terhadap obat sangatlah penting, penderita DM mengatakan merasa bosan, dan merasa dirinya sudah makan obat secara teratur dan mematuhi diet tapi tetap saja gula darahnya masih meningkat.

Padahal pengetahuan, motivasi dan kepercayaan penderita DM yang tidak baik akan berdampak pada ketaatan yang rendah terhadap program diet. Penderita DM yang tidak teridentifikasi mempunyai gejala berfikir bahwa mereka sudah merasa sembuh dan sehat. Sedangkan penderita DM dengan pengetahuan yang cukup baik tentang kepatuhan dalam perawatan DM maka secara langsung akan bersikap positif dan menuruti aturan pengobatan dan muncul keyakinan untuk sembuh. ${ }^{5}$

\section{Faktor Pemungkin}

Hasil penelitian menunjukan bahwa dari 97 responden terdapat sebagian besar dari responden yaitu berjumlah 61 orang $(62,89 \%)$ memiliki faktor pemungkin (perilaku kesehatan) yang tidak baik. Hal ini menunjukan masih ada penderita DM di
Poliklinik Penyakit Dalam RSUD Dr. M. Yunus yang memiliki perilaku kesehatan yang tidak baik. Peneliti melihat petugas kesehatan masih belum maksimal melakukan penyuluhan, pendekatan diri kepada penderita DM, karena peneliti mendapatkan informasi dari pelayanan primer di Puskesmas, petugas kesehatan hanya melakukan penyuluhan kepada masyarakat hanya sebulan sekali itupun tidak sepenuhnya tentang DM. Sedangkan petugas medis di Poliklinik Penyakit Dalam RSUD Dr. M. Yunus hanya memberikan obat tanpa memberikan edukasi, dan penderita DM pun datang berobat bila gula darahnya sudah meningkat sehingga melanjutkan minum obat DMnya. Faktor pemungkin ini bisa berupa tersedianya sarana prasarana, meliputi pengobatan, penyuluhan kesehatan, laboratorium dan usaha peningkatan gizi serta penanganan diluar gedung antara lain kegiatan perawatan kesehatan masyarakat dan pembinaan peran serta masyarakat sehingga memungkinkan timbulnya perilaku kesehatan bagi penderita DM. Penyuluhan kesehatan yang dilakukan sebulan sekali di Puskesmas cenderung membuat penderita DM kurang mendapatkan informasi dan pengetahuan yang baik mengenai diet DM. Perilaku kesehatan ini sangat penting untuk penderita DM, dimana 
rendahnya kunjungan untuk mengontrol kadar gula darah baik ke Puskesmas maupun ke Poliklinik Penyakit Dalam RSUD Dr. M. Yunus juga dapat mempengaruhi dalam peningkatan kadar gula darah pada penderita DM. Bila perilaku kesehatan tidak baik akan berdampak pada peningkatan kadar glukosa darah dan kepatuhan diet pada penderita DM. ${ }^{4}$

\section{Faktor Penguat}

Hasil penelitian menunjukan bahwa dari 97 responden terdapat hampir sebagian dari responden yaitu berjumlah 36 orang $(37,11 \%)$ memiliki dukungan keluarga yang tidak baik. Hal ini menunjukan masih ada penderita DM di Poliklinik Penyakit Dalam RSUD Dr. M. Yunus yang memiliki dukungan keluarga yang tidak baik.

Peneliti melihat masih ada penderita DM yang pergi sendiri ke Poliklinik Penyakit Dalam RSUD Dr. M. Yunus, dirumah penderita DM mengatakan masih makan mie instan dan keluarga penderita juga masih menggunakan penyedap rasa pada saat memasak. Padahal keluarga sangatlah berperan penting dalam menentukan cara asuhan yang diperlukan oleh anggota keluarga yang sakit.

Dukungan keluarga pada penderita DM yang tidak baik, cenderung berpengaruh besar pada penderita DM dalam ketaatan melakukan perawatan DM, sebab keluarga adalah orang terdekat dan sering berinteraksi, sehingga motivasi atau dukungan yang diberikan keluarga sangatlah besar artinya terhadap ketaatan pasien untuk mengontrol kadar gula darah secara rutin dengan dukungan dari keluarga juga perasaan individu yang mendapatkan perhatian, disenangi, dihargai dan termasuk bagian dari masyarakat. ${ }^{6}$

Jenis-jenis dukungan keluarga yaitu :

1. Dukungan emosional

Keluarga sebagai sebuah tempat yang aman dan damai untuk istirahat dan pemulihan serta membantu penguasaan terhadap emosi yang meliputi ungkapan empati, kepedulian dan perhatian terhadap anggota keluarga yang menderita DM.

2. Dukungan penghargaan (penilaian)

Keluarga bertindak sebagai bimbingan umpan balik membimbing dan menengahi pemecahan dan sebagai sumber dan validasi identitas anggota.

3. Dukungan instrumental

Keluarga merupakan sumber pertolongan praktis dan konkrit yang mencangkup bantuan seperti dalam bentuk uang, peralatan, waktu, modifikasi lingkungan maupun menolong dengan pekerjaan waktu mengalami stres.

4. Dukungan informatif 
Keluarga berfungsi sebagai sebuah kolektor dan diseminator (pengantar) informasi tentang dunia yang mencangkup dengan bentuk dukungan yang diberikan oleh keluarga untuk memberikan dorongan semangat, pemberian nasehat atau mengawasi tentang pola makan sehari-hari dan pengobatan.

\section{Ketidakpatuhan Diet}

Hasil penelitian menunjukan bahwa dari 97 responden terdapat sebagian besar dari responden yaitu berjumlah 68 orang $(70,10 \%)$ tidak patuh terhadap diet. Hal ini menunjukan masih ada penderita DM di Poliklinik Penyakit Dalam RSUD Dr. M. Yunus yang tidak patuh terhadap diet DM.

Ketidakpatuhan diet pada penderita DM, berpengaruh terhadap pengobatan dan kadar gula darah pada penderita DM. Kepatuhan diet sangatlah penting untuk mempertahankan kadar gula darah senormal mungkin serta mengusahakan agar berat badan penderita mencapai batas normal. ${ }^{7}$

Kemampuan penderita DM untuk mengontrol kehidupannya dapat mempengaruhi tingkat kepatuhan. Seseorang yang berorientasi pada kesehatan cenderung mengadopsi semua kebiasaan yang dapat meningkatkan kesehatan dan menerima regimen yang akan memulihkan kesehatannya. Orang yang melihat penyakit sebagai kelemahan akan menyangkal penyakit atau hadirnya penyakit itu. Pengingkaran ini dapat mempengaruhi terjadinya ketidakpatuhan. Ketidakpatuhan merupakan salah satu masalah yang berat dalam dunia medis, dan oleh karena itu sejak tahun 1960an sudah mulai diteliti di negara-negara industri. Secara umum, ketidakpatuhan meningkatkan risiko berkembangnya masalah kesehatan dan dapat berakibat memperpanjang atau memperburuk penyakit yang sedang diderita. ${ }^{5}$

\section{Hubungan Faktor Predisposisi dengan}

\section{Ketidakpatuhan Diet DM}

Hasil penelitian menunjukan bahwa dari 97 responden terdapat 59 orang responden $(60,8 \%)$ yang pengetahuannya tidak baik juga memiliki ketidakpatuhan terhadap diet. Hasil Chi-square $\left(x^{2}\right)$ yaitu Continuity Correction diperoleh nilai $\rho=0,000$ $(\rho<0,05)$ yang berarti Ha diterima bahwa ada hubungan yang bermakna antara faktor predisposisi (pengetahuan) dengan Ketidakpatuhan Diet Pada Penderita DM di Poliklinik Penyakit Dalam RSUD Dr. M. Yunus Kota Bengkulu tahun 2013.

Hal ini sependapat dengan (Notoatmodjo, 2007) menyatakan bahwa rendahnya pengetahuan penderita DM 
terhadap kepatuhan diet membuat penderita tidak mengetahui tentang manfaat kepatuhan diet dan perawatannya, sedangkan jika pengetahuan penderita DM baik tentang kepatuhan diet dalam perawatan maka secara langsung akan bersikap positif dan menuruti aturan pengobatan dan muncul keyakinan untuk sembuh. ${ }^{5}$

Semakin tinggi tingkat pengetahuan individu maka semakin mudah individu yang bersangkutan untuk dapat menerima informasi atau saran dari luar. Informasi itu dapat berbentuk sebuah penyuluhan atau leaflet yang diberikan oleh professional kesehatan guna untuk meningkatkan pengetahuan tentang kesehatan. Dengan pengetahuan yang semakin tinggi dapat menstimulasi motivasi dan meningkatkan motivasi untuk meningkatkan ketaatan. ${ }^{10}$

\section{Hubungan Faktor Pemungkin dengan}

\section{Ketidakpatuhan Diet DM}

Hasil penelitian menunjukan bahwa dari 97 responden terdapat 61 orang $(62,89 \%)$ yang perilaku kesehatanya tidak baik juga memiliki ketidakpatuhan terhadap diet. Hasil uji Chi-square $\left(x^{2}\right)$ yaitu Fisher's exact test diperoleh nilai $\rho=0,000(\rho<0,05)$ yang berarti Ha diterima bahwa ada hubungan antara faktor pemungkin (perilaku kesehatan) dengan Ketidakpatuhan Diet Pada Penderita
DM di Poliklinik Penyakit Dalam RSUD Dr. M. Yunus Kota Bengkulu tahun 2013.

Hal ini sependapat dengan (Green dan kreuter, 2005) menyatakan bahwa rendahnya perilaku kesehatan penderita DM terhadap ketidakpatuhan diet dapat mempengaruhi kepatuhan diet pada penderita DM di Poliklinik Penyakit Dalam RSUD Dr. M. Yunus Kota Bengkulu tahun 2013, sedangkan jika perilaku kesehatan baik maka dapat meningkatkan kepatuhan diet pada penderita DM.

Kepatuhan yaitu tingkat/derajat dimana penderita DM mampu melaksanakan cara pengobatan dan perilaku yang disarankan oleh dokter atau tim kesehatan lainnya. ${ }^{8}$ Kepatuhan merupakan tingkat dimana perilaku seseorang sesuai dengan saran praktisi kesehatan. Kepatuhan mengacu pada proses dimana seorang penderita DM mampu mengasumsikan dan melaksanakan beberapa tugas yang merupakan bagian dari sebuah regimen terapeutik. Kepatuhan seseorang terhadap suatu regimen terapi bergantung pada berbagai variabel seperti, kompleksitas terapi dan kesesuaian penderita DM dengan program tersebut serta nilai-nilai penderita DM mengenai kesehatan.

\section{Hubungan Faktor Penguat dengan Ketidakpatuhan Diet DM}


Hasil penelitian menunjukan bahwa dari 97 responden terdapat $36(37,11 \%)$ yang dukungan keluarganya tidak baik juga memiliki ketidapatuhan terhadap diet. Hasil uji Chisquare $\left(x^{2}\right)$ yaitu Continuity Correction diperoleh nilai $\rho=0,000(\rho<0,05)$ yang berarti bahwa Ha diterima yaitu ada hubungan antara faktor penguat (dukungan keluarga) dengan Ketidakpatuhan Diet Pada Penderita DM di Poliklinik Penyakit Dalam RSUD Dr. M. Yunus Kota Bengkulu tahun 2013.

Hal ini sependapat dengan (Friedman, 2007) yang menyatakan bahwa bila dukungan keluarga penderita DM baik dapat membantu bagi penderita DM dalam ketaatan melakukan perawatan DM. ${ }^{6}$ Sedangkan dari hasil penelitian didapatkan rendahnya dukungan keluarga terhadap ketidakpatuhan diet dapat mempengaruhi ketidakpatuhan diet pada penderita DM di Poliklinik Penyakit Dalam RSUD Dr. M. Yunus Kota Bengkulu tahun 2013. Kurangnya perhatian keluarga terhadap penderita DM dan ketidakpatuhan penderita DM dalam hal mengatur diet rendah gula akan mudah terjadi komplikasi DM, untuk itu dukungan keluarga sangatlah penting karena keluarga dapat mengenal masalah, dapat mengambil keputusan, melakukan pengobatan pada anggota keluarga yang sakit, mempertahankan suasana lingkungan rumah dan menggunakan fasilitas kesehatan yang ada keluarga juga harus dapat memberikan motivasi pada penderita agar penyakitnya tidak bertambah parah. ${ }^{10}$

Hal ini juga sependapat dengan (Niven, 2007) Keluarga memberikan perawatan kesehatan yang bersifat prefentif dan secara bersama - sama merawat anggota keluarga yang sakit karena keluarga merupakan unit terkecil dari masyarakat yang paling dekat hubungannya dengan penderita. Dengan adanya dukungan keluarga dapat meningkatkan kepatuhan penderita dalam penatalaksanaan diet. $^{9}$

Dukungan keluarga merupakan sistem pendukung utama yang memberikan perawatan langsung pada setiap keadaan sehat dan sakit klien. Umumnya keluarga meminta bantuan kepada tenaga kesehatan apabila mereka tidak sanggup lagi merawatnya. Perawatan kesehatan keluarga adalah tingkat perawatan kesehatan masyarakat yang ditujukan kepada keluarga sebagai unit atau satu kesatuan yang dirawat dengan sehat sebagai tujuannya dan melalui perawatan sebagai sarananya $^{11}$

Mematuhi program diet/pola makan adalah hasil dari proses perubahan perilaku. Perilaku yang menetap memerlukan motivasi dan keyakinan yang kuat. Penderita DM 
mungkin saja memiliki pengetahuan mengenai suatu prosedur pengobatan, tetapi tidak berkemauan dan tidak mampu melaksanakannya karena adanya reaksi negatif terhadap kondisi/cara perawatan penyakit. $^{7}$

Hal ini dapat dilihat bahwa responden dengan dukungan keluarga yang tidak baik, sebagian besar tidak mematuhi program diet penyakit Diabetes Mellitus, sebab keluarga adalah orang terdekat dan sering berinteraksi, sehingga motivasi atau dukungan yang diberikan keluarga sangatlah besar artinya terhadap ketaatan pasien untuk mengontrol kadar gula darah secara rutin dengan dukungan dari keluarga juga perasaan individu yang mendapatkan perhatian, disenangi, dihargai dan termasuk bagian dari masyarakat. $^{6}$

\section{KESIMPULAN}

Berdasarkan analisis data univariat didapatkan: 60,8\% pasien DM memiliki faktor predisposisi (pengetahuan) tidak baik, 62,89\% pasien DM memiliki faktor pemungkin (perilaku kesehatan) tidak baik, 37,11\% pasien DM memiliki faktor penguat (dukungan keluarga) tidak baik, 57,4 \% pasien DM tidak patuh terhadap diet DM. Dari analisis data bivariat dapat disimpulkan: adanya hubungan faktor predisposisi (pengetahuan), faktor pemungkin (perilaku kesehatan), faktor penguat (dukungan keluarga) dengan ketidakpatuhan diet pada penderita DM di Poliklinik Penyakit Dalam RSUD Dr. M. Yunus Kota Bengkulu tahun 2013 dengan nilai $\rho=$ 0,000

\section{DAFTAR RUJUKAN}

1. Bengkulu. Profil Dinas Kesehatan Propinsi Bengkulu. Propinsi Bengkulu: Kementerian Kesehatan RI; 2011.

2. World Heatlh Organization (WHO). Prevalensi Penderita Diabetes Mellitus di Indonesia; Faktor penyebab DM. WHO; 2009.

3. Suyono. Memperbaiki Taraf Kesehatan Secara Global. Jakarta: EGC; 2006

4. Green L.W, Kreuter M. Health promotion planning: an educational and environmental approach. Mayfield publishing company, 2nd edition; 2005.

5. Notoadmojo. Metode Penelitian Kesehatan. Jakarta : Trineka Cipta; 2007.

6. Friedman. Faktor Penyebab Diabetes Mellitus (internet).(place unknown): Friedman; 2007. Diakses dari http://www. Kesehatan. Co.id

7. Widharti. Gaya Hidup Diabetes Mellitus. Jakarta: Trineka Cipta; 2007.

8. Smet. Chronic Disease Patient Know Ledge and the effect on the demand for 
Physicln Service (internet). (place

unknown) Smet; 2011. Available from:

http//:www. Acedemyhelth,org.

9. Niven. Diabetes : Informasi Lengkap Untuk Penderita dan Keluarganya. Jakarta: PT. Gramedia Pustaka Utama; 2007.

10. Mudita. Mengenal Diabetes Mellitus . Edisi 2. Jakarta : Arean press; 2009.

11. Balion. Keperawatan Keluarga. Jakarta, EGC; 2007. 